\title{
páginas salvadas
}




\title{
Gilda de Mello e Souza
}

\section{Moda y cultura femenina en el siglo XIX}

\author{
Fashion and women's culture in the 19th century \\ Moda e cultura feminina no século XIX
}

\section{Traducción de Eleonora Cróquer}

Gilda de Mello e Souza (São Paulo, 1919-2005) fue profesora titular y emérita de la Facultad de Filosofía, Letras y Ciencias Humanas, Departamento de Filosofía de la Universidade de São Paulo (USP). Doctora en Ciencias Sociales por la USP. Autora de $O$ tupi e o alaúde: uma interpretação de Macunaíma (Editora 34, 2009; 1. ${ }^{\mathrm{a}}$ ed. 1979), Exercícios de leitura (Editora $34 ; 1 .{ }^{\mathrm{a}}$ ed. 1980), Os melhores poemas de Mário de Andrade (selección y presentación, Global Editora, 1988), O espírito das roupas: a moda no século XIX (Companhia das Letras, 1987), A ideia e o figurado (Editora 34, 2005).

Eleonora Cróquer es profesora del Departamento de Lengua y

Literatura en la Universidad Simón Bolívar, Caracas. Doctora en Filología Hispanoamericana por la Universitat de Valencia, España. Es autora de varios artículos en revistas especializadas y autora de los libros El gesto de Antígona o la escritura como responsabilidad (Clarice Lispector, Diamela Eltit, Carmen Boullosa) (Cuarto Propio, 2000), Escrito con rouge: Delmira Agustini (18861914). Artefacto cultural (Beatriz Viterbo Editora, 2010). Correo electrónico: elecrope@gmail.com

Este texto corresponde a un capítulo titulado "A cultura femenina", del libro O espíritu das roupas (São Paulo: Companhia das Letras, 1987). En español, publicado originalmente en Escritura 16.31-32 (enero-diciembre de 1991), Caracas, Universidad Central de Venezuela, dossier: "Literatura femenina", coordinado por Margara Russotto.

Documento accesible en línea desde la siguiente dirección: http://revistas.javeriana.edu.co

doi:10.11144/Javeriana.CL18-36.mcfs

\section{Cómo citar esta traducción:}

Mello e Souza, Gilda de. "Moda y cultura femenina en el siglo XIX". Trad. Eleonora Cróquer. Cuadernos de Literatura 18.36 (2014): 352-366. http://dx.doi.org/10.11144/ Javeriana.CL18-36. http://dx.doi.org/10.11144/Javeriana.CL18-36.mcfs 
EN EL SIGLO XIX la moda continúa siendo, para el grupo femenino, la gran arma en la lucha entre los sexos y en la afirmación del individuo dentro del grupo. Una serie de factores, como el advenimiento de la burguesía, la mejora de las vías de comunicación y el número creciente de figurines - cuyos modelos de modas eran copiados por los periódicos y revistas de la provincia y de otros países- hicieron que esta no fuese más el privilegio de una clase y se difundiera fuera de los grandes centros de irradiación cultural ${ }^{1}$. Por otro lado, el desarrollo de la industria había liberado al sexo femenino de una serie de actividades productivas que hasta entonces se realizaban en el ámbito doméstico. El centro urbano abastecía con más facilidad y más económicamente el pan, el tejido, el encaje, el vestido acabado, el sombrero; y la creciente especialización de las funciones creaba una serie de nuevos empleos, tanto en las fábricas como en los hogares, atendidos por las mujeres del nuevo proletariado. Repentinamente, la mujer burguesa se encontró sin oficio, y su único objetivo - ahora que en las clases medias y altas había perdido su valor económico transformándose en grupo dependiente- era casarse. Tal situación favorecía el desarrollo de aquellos recursos que entran en juego en la competencia sexual y, en el breve espacio de tiempo que mediaba entre la vida de la niña y la de la señora, la joven se entregaba al aprendizaje de la música y de las buenas maneras, al interés por los vestidos, viviendo la expectativa de la llegada del marido.

Pero decía un proverbio inglés: "Marry your sons when you will, and your daugthers when you can". Y existían casos en los cuales, a pesar de que madres e

1 Hasta la segunda mitad del siglo XVIII, París, que era entonces el gran centro creador de modas, enviaba a las grandes ciudades europeas, de tiempo en tiempo, pequeños maniquíes vestidos con las últimas creaciones. Evidentemente tal proceso rudimentario hacía que el resto del mundo tuviese siempre un considerable atraso en relación con la moda reinante en la capital francesa. La invención de los figurines solucionó el problema. Habiendo surgido a fines de siglo, en Inglaterra y en Francia, en breve se multiplicaron, convirtiéndose en uno de los elementos indispensables de la mujer elegante. Quizás el más antiguo de todos sea The Lady Monthly Museum, aparecido en 1798, que luego rivalizó con Le Beau Monde y La Bele Assemblée. Más tarde aparecen The English Woman's Domestic Magazin, Le Courrier de Dames, Le Moniteur de La Mode, Les Modes Parisiennes, Le fournal des Demoiselles, Le Magazin des Demoiselles, Le fournal des Dames. También revistas como Le Follet Nouveau Paris de Marcier y The Young Englishwoman traían siempre sus patrones de moda. Lo mismo ocurría con nuestras publicaciones, como la Revista Popular y O Novo Correio de Modas, que reproducen las admirables acuarelas de Anais Toudouze, haciendo una pormenorizada descripción de los trajes. Por eso, en Brasil, la entrada del paquete inglés era esperada con sobresalto; pues junto con las noticias internacionales llegaban las reglas de la elegancia. La crónica social del 16 de marzo de 1860, de la Revista Popular, abre con la gran noticia de la última revolución producida en las altas y aristocráticas regiones de la moda: la emperatriz Eugenia había abandonado la crinolina. 
hijas se empeñasen en la realización de ese deseo, el marido no llegaba. Las casas se llenaban del ruido de las solteronas ejercitando sus cualidades musicales, las canastas se abarrotaban de enaguas y corpiños ricamente bordados, y la pregunta dolorosa de centenares de mujeres se perdía en el aire: ¿Qué hacer con mi vida? El matrimonio era entonces una especie de favor que el hombre concedía a la mujer; el único medio de adquirir estatus económico y social; pues quien no se casaba era mujer fracasada y tenía que conformarse con una vida gris de solterona, acompañando a la madre en sus visitas, entregándose a los bordados interminables y a la educación de los sobrinos. O bien, en sociedades donde el movimiento de emancipación estaba más adelantado, como en Inglaterra, a una vida de humillación como institutriz.

Pero, de no casarse, la mujer veía disminuido su prestigio en la sociedad, y al dedicarse al trabajo remunerado descendía inmediatamente de clase. Fuera del tejido, la enseñanza particular era la única posibilidad de ganarse la vida ${ }^{2}$. Sin embargo, un anatema pesaba sobre esa pálida criatura, que podía ser reconocida a simple vista por el vestido sencillo y discreto, por el sombrero de paja sostenido con un velo marrón o verde y por el rostro donde se empapaba una mirada fija de desesperación. Pobre ser mal pagado, frecuentemente se le imponía la obligación de cambiar de nombre, como para perdonarlo del crimen de haber descendido de clase, disfrutaba de menos regalías que una criada, y sus labores iban de la enseñanza de la música al remiendo de las ropas ${ }^{3}$.

A la mujer del siglo XIX le quedaba, por tanto, la sola posibilidad del matrimonio. Esta única alternativa permitida al sexo femenino no podía dejar de favorecer el desarrollo intensivo del arte de la seducción. Y si ahora la moda era accesible a todos a través de los grabados de colores que publicaba la revista de señoras, también proliferaban por todas partes los libros de etiqueta característicos de una clase que se

2 En 1850 existían, en Inglaterra, 21.000 institutrices registradas, provenientes en su mayoría de familias del clero y de familias empobrecidas por negocios fracasados (Percival 9). Para el problema de la institutriz, véanse también Viola Klein, principalmente el capítulo II; los libros de Cunnington, sobre todo Feminine Attitudes (118-211), The Perfect Lady y Feminine Fig-Leaves; Thackeray, Vanity Fair; Charlotte Brontë, fane Eyre.

3 He aquí como Charlotte Brontë, institutriz e hija de pastor, se refiere, en una carta para su hermana, a su triste condición: "En mi última carta dije que Mrs. Sidewick no me conocía. Empiezo a pensar ahora que él no pretende conocerme: que no se incomoda conmigo a no ser en la medida en que puede darme la mayor cantidad de trabajo posible; así, me ahoga en océanos de costura, metros y metros de cambray para coser, tocados de muselina para hacer y, además de todo, muñecas para vestir... Veo ahora con mayor claridad que antes que una institutriz no tiene existencia, no es considerada un ser racional, excepto en lo que se refiere a los fatigantes deberes que tiene que cumplir" (Percival 118). 
formaba y donde este sutil esquema del comportamiento aún no había sido impuesto por la tradición. La dificultad estaba exactamente en conciliar el arte de seducir con las reglas de la etiqueta. Pues si por un lado conseguir marido era una necesidad imperiosa, para lo cual la mujer movilizaba un arsenal de sedas y atrevimientos, por el otro, la rigidez de la moral vigente se oponía como un obstáculo infranqueable al único objetivo digno de anhelar en la vida. Una serie de reglas básicas orientaban los encuentros entre los sexos, enseñando a las mujeres cómo portarse delante de los hombres, cómo aceptar el cortejo, aconsejando que las relaciones "fuesen establecidas con excesiva cautela", que las cabezas no se acercasen demasiado leyendo el mismo libro, que las muchachas no "aceptasen sin necesidad la ayuda para cubrirse con la capa, el chal, calzarse los botines", etc. (Schlesinger 25$)^{4}$.

Este panorama general del siglo XIX, que ofrecía a la mujer una única posibilidad de realización - el matrimonio - y, al mismo tiempo, le coartaba todas las posibilidades no solo de iniciativa sino de propiciar situaciones favorables, desarrolló en el grupo femenino una curiosa técnica de avances y retiradas, de entregas parciales, un darse negándose, que es la esencia de la coquetterie. La necesidad de agradar la condujo a emplear "todos los recursos posibles, desde los más sutiles estímulos espirituales, hasta las más insistentes exhibiciones" (Simmel 56 ). A servirse simultáneamente de los lindos brazos y de los codos tersos cuando punteaba el arpa; del encanto de la voz en las tres o cuatro modinbas memorizadas a duras penas, o de las sonatas de piano, donde el cuerpo, entregándose a la música, insinuaba abandonos más completos e inconfesables. A combinar el ofrecimiento y la negación, en el ritmo sinuoso del caminar, como en el último decenio del siglo, en el cual los vestidos de cola escondían los miembros, imprimiendo a la figura un ritmo pélvico imitado de las grandes cocottes de la época.

Se sabe que la vestimenta se origina menos por el pudor y la modestia que por un viejo truco que pretende, a través del ornamento, llamar la atención sobre ciertas partes del cuerpo ${ }^{5}$. Efectivamente la moda comienza en realidad cuando, a partir del siglo XV, se descubre que la ropa puede ser utilizada como un compromiso entre el exhibicionismo y su recato (la modestia) ${ }^{6}$. Desde entonces se han

4 Véase todo el capítulo titulado "Republican Etiquette" (Schlesinger). Véase de nuevo Cunnington (Feminine Attitudes 21 ss.). Entre otros manuales de buenas maneras podemos citar, también en Inglaterra: The Etiquette of Courtship and Marriage, The Girl's Book of Diversions, The Handbook of Toilet (1841), etc.

5 Las teorías que ven en la modestia o en la lucha contra el clima el origen de la vestimenta están hoy superadas. Véase el artículo de Ruth Benedict, "Dress".

6 Para este punto de vista véanse los estudios de J. C. Flügel "De la valuer affective du vetement", The Psycology of Clothes y "Compte-rendu" (66 ss.). 
manifestado dos tendencias en las variaciones sucesivas de la moda: la de descubrir el cuerpo, logrando que el exhibicionismo triunfe sobre el pudor, que el instinto sexual se expanda en formas más realísticas de expresión; y la de cubrirlo de disfraces, bajo la coacción del puritanismo y el decoro ${ }^{7}$. La primera actitud, bastante rara, la mayoría de las veces acompaña a las grandes crisis sociales, al resquebrajamiento de la moral, como sucede en los periodos posteriores a las guerras napoleónicas y al conflicto de 1914. La segunda, más común, caracteriza casi todo el siglo XIX y parte del XX. Sin embargo, aquí más que allá, es evidente ese compromiso del cual hablábamos, que conduce a una auténtica concentración, a la acentuación simbólica de las características sexuales. Pues si ahora el cuerpo se revela más, liberado a través de los velos tenuísimos de la Regencia, es porque hubo algo así como un desplazamiento de los intereses exhibicionistas del cuerpo desnudo hacia la vestimenta. Y si la ropa cubre el cuerpo de la mujer, concienzudamente, no por eso deja de acentuarle las características sexuales, aumentándole las caderas, primero por la gran cantidad de enaguas, vuelos y encajes, luego por la crinolina, apretándole la cintura para acentuarle mejor la pequeñez a través del contraste con las mangas excesivas. $\mathrm{O}$ transformándola, con el volumen del armador, en una Venus Calipigia monstruosa (Flügel 250). Por lo tanto, el ritmo erótico, que consiste en llamar la atención sobre cada parte del cuerpo sucesivamente, manteniendo el instinto sexual siempre ardiente, aquí se relaciona sobre todo con la parte que el traje acentúa y no con la que desnuda ${ }^{8}$.

7 La teoría de Flügel es, de cierta manera, retomada por Cunnington en sus libros. A estas dos actitudes corresponderían dos formas en la vestimenta: la vertical y la gótica (o la clásica y la sentimental). Ambas son encontradas en el siglo XIX. Véase principalmente English Wome's Clothing in the Nineteenth Century, en especial la introducción (Cunnington).

8 Hoy en día, cuando los tabúes del cuerpo y de la moral han cedido, y no existiendo límites muy nítidos del pudor, es necesario, para mantener la tensión entre los sexos, variar constantemente la porción de piel expuesta. El compromiso entre el exhibicionismo y el recato encuentra una nueva forma de expresión en el ritmo acelerado de la moda. Pues a medida que las diferentes partes del cuerpo trasponen la zona de resistencia del pudor, van, progresivamente, perdiendo su contenido emocional. Así ocurrió con los pies, el tobillo, los brazos; el hábito transformó esas regiones otrora perturbadoras en regiones estériles que el hombre contempla sin emoción. De allí la necesidad de la moda de variar, ininterrumpidamente, las porciones del cuerpo exhibidas. Las piernas femeninas, por ejemplo, que durante siglos fueron como el último reducto del pudor de la mujer, se liberan en el decenio de los 20 de este siglo y, desde entonces, presenciamos un periodo de abierta ostentación de los miembros inferiores, que culminará en el 28, cuando los vestidos alcanzan las rodillas y el hombre contempla, aburrido, toda un área que le era prohibida. Sin embargo, el busto, que fuera abolido en los vestidos cilíndricos de la postguerra, y el cuello, que no se mostraba en las blusas de "chemisier" y en la ropa sexuada de corte americano que dominó el mercado hasta el reciente renacimiento de la costura francesa, súbitamente se acentúan y se desnudan, mientras la falda desciende a la 
Por otro lado, la vestimenta seguirá la tendencia general de la elegancia, marcando la oferta interrumpida a través de los velos que escondían el rostro a medias, combinando la falta de pudor de los escotes con la multiplicación de las enaguas. Y si la fragilidad excesiva de la cintura solicitaba un brazo que la contornease, existía siempre el obstáculo infranqueable del armador entre el gesto solicitado y el cuerpo de la mujer.

Esta poderosa fortaleza de acero era, además, un nuevo elemento en el arte de la seducción; pues animada por una constante oscilación, bien cubría o bien revelaba los pies, creando al ras del suelo una inquietante zona de espera. La literatura de esa época nos ofrece innumerables ejemplos de pies indiscretos, "enterrados en zapatitos de satén" (Macedo), pellizcando el borde de la enagua9", cuya irrupción perturbadora en la compacta estructura femenina los transformaba en elementos altamente eróticos ${ }^{10}$. Lo mismo acontecía con la punta de los

altura estipulada por Christian Dior: a treinta centímetros del suelo. Escondidas durante un breve espacio de tiempo, resurgen de nuevo las piernas a principios de 1950. Hoy, por lo tanto, el ritmo erótico consiste en abandonar constantemente la "zona erógena" que se transformó en "zona estéril". La finalidad de la moda es, en gran parte, esa búsqueda sin fin. (Para el ritmo erótico, consúltese James Laver, Taste and Fashion, en especial la pagina 201; del mismo autor, Letter to a Girl on the Future of Clothes; Marañon, Gordos y flacos).

9 "El pie se escondía en una pantufla de satén que a veces pellizcaba el borde de la falda" (Alencar, Senhora 101).

10 Véanse, por ejemplo, los siguientes fragmentos: "eran azules las cintas del cabello y de la cintura, como el satén de un zapato raso que le calzaba el pie como la guarnición de una perla" (Alencar, Senhora 180).

"En lugar de las pantuflas de pelusa que acostumbraba usar en la casa; en privado, calzaba un botín de merino oscuro, que le quedaba admirable, porque ella tenía el más lindo pie del mundo" (Alencar, Lucíola).

"Muchacha bonita es Nhanha Carlotinha! ¡Era sí! ¡No tiene comparación! Piecito de niña: cinturita bien hechecita ¡no hace falta apretar! El zapatito de ella parece juguete de muñeca" (Alencar, O Demonio familiar).

"Su vestido que apunta al mayor grado de simplicidad, diseñaba sus formas graciosas, cometiendo apenas el error imperdonable de, por ser tan largos, esconder sus pequeños pies en zapatos de lana negra" (Macedo, Rosa 18).

"Y que su pecado contra la modestia reinante no era sino un medio sutil del que se aprovechaba para dejar ver el piecito mejor hecho y más pequeño que se pueda imaginar" (Macedo, $A$ moreninha 214).

"Sentada, se le veía la mitad del pie, zapato bajo, media de seda, cosas todas que pedían misericordia y perdón" (Machado de Assis, Quincas Borda).

"Unos zapatos, por ejemplo, unos zapatitos bajos de trenzas oscuras que se cruzaban en el empeine y el principio de la pierna" (Machado de Assis, Dom Casmurro 289).

"Se le veía el perfil correcto y pensativo, la curva suave del brazo y la punta indiscreta y curiosa del zapatito bajo que traía" (Machado de Assis, Helena 115). 
encajes que el más ligero movimiento del cuerpo hacía asomar en el ruedo de la falda o en la línea del escote.

El juego del escondite con el cual la mujer del siglo XIX llamaba la atención sobre sus encantos anatómicos, envolviéndolos en misterios a través de la reticencia y el disfraz, la transformaba en una verdadera caja de sorpresas. Durante el día los sustos eran menores, pues imperaba la simplicidad y el recato: "Su traje habitual en estos paseos era de merino oscuro, mantilla de seda negra y un sombrero de paja con lazos azules" (Alencar, Lucíola). Los cuellos subían muy discretos hasta la garganta y los puños cerraban la muñeca donde, muchas veces, la mano escondida en el guante no se mostraba: "Lucía traía en esa mañana un traje casi severo: vestido oscuro, cerrado y de mangas largas, con pocos volantes, collarín simple y puños de lino bordados: cabellos negligentemente recogidos en una vasta trenza, sin ornamento alguno" (Alencar, Lucíola).

Con la noche, en cambio, surgía una modificación arbitraria en las reglas de la decencia, y siempre existía la esperanza de que en el teatro, o en el baile, el vestido subrayase mejor la gracia del cuerpo y los escotes dejasen sobresalir los brazos y cuellos desnudos: "En cuanto a Adelaide, por toda la satisfacción de brillar, no reparaba en la impaciencia de la amiga, no se percataba de que el excesivo recogimiento de su corpiño, con el requiebro que imprimía al talle, le desnudaba casi todo el busto a los ojos del hombre a quien le daba la espalda" (Alencar, Senhora 267). Entonces, estallaba un sinfín de recursos, inventando flores en los cabellos y los senos: "Estaba peinada con rizos y sobre su cabeza ostentaba orgullosa una rosa-constantino... traía también, prendida a la altura del pecho, una flor en todo semejante a la de la cabeza" (Macedo, Rosa 68) ${ }^{11}$. O descubriendo la nuca, y sirviéndose de las joyas para llamar la atención sobre ciertas zonas del cuerpo:

Sus opulentos cabellos recogidos en la nuca por una diadema de ópalos, caían en cascada sobre los blancos hombros redondeados... Ceñía el brazo torneado que la manga recogida descubría hasta la curva, una pulsera también de ópalos, como el tembloroso collar y los saltos de los largos pendientes que temblaban en la punta de las orejas de nácar. (Macedo, Rosa 78)

Semejante contraste entre la severidad del vestido de día y la sorpresa del traje de noche reforzaba el ritmo erótico, el juego de entregas parciales, del

11 Y también en la página 71 de Rosa: "La bella joven venía peinada con cintas [...] su cabeza se coronaba con una guirnalda de margaritas; $[\ldots]$ se mostraba en su pecho una orgullosa margarita". 
cual se valía la mujer para, sin ofender la moral burguesa que exigía guardar las apariencias, ofrecerse al mismo tiempo a una cantidad de hombres. Además, esa posesión a distancia, realizada por la vestimenta en general y particularmente por el escote - y que funcionaba tanto para las solteras como para las casadas-, fue tal vez uno de los más poderosos elementos de equilibrio de la sociedad de aquel tiempo. Y hacía de la reunión mundana el momento agudo en la lucha amorosa.

A las institutrices también les estaba negada esta posibilidad. Confinadas al austero vestido oscuro que no les hacía ninguna concesión, se veían relegadas a la existencia diurna del recato, retirándose silenciosas a su rincón, cuando se iluminaba el gas de los salones. No sorprende, por consiguiente, que hubiesen desarrollado un mecanismo de compensación, imaginando un universo regido por la supremacía de los valores morales. Que hubiesen - pobres frustradas colocadas por debajo de su clase y fuera de la competencia amorosa-dado origen al curioso movimiento de autovalorización, que presenciamos en la literatura de la época con la serie de institutrices maltratadas y de voluntad férrea. La más desgarradora de todas quizá sea Jane Eyre, la joven de gran temple moral, fea pero inteligente, que a través de sus cualidades espirituales vence a la bella rival y triunfa en el corazón impetuoso de Rochester. Lo que significa la recuperación de posiciones perdidas de todo un grupo que se sentía explotado y puesto al margen de la vida. Este grupo no participaba de ninguno de los privilegios gozados por la mujer que tanto endulzaban la existencia: derecho al ocio, a ser bella, a resplandecer en los vestidos y competir con las otras mujeres en la lucha entre sexos, injusticia que la clarividente Becky Sharp pronto percibió abandonando las normas de su clase; puesto que la lucha tenía que llevarse a cabo en otro campo, y las armas poderosas eran la gracia de las maneras y el encanto de los brazos (Thackeray, Vanity Fair).

Sin embargo, en un fenómeno complejo como la moda no existe un límite nítido entre la función que esta desempeña en la lucha sexual y la importancia que adquiere en la realización completa del individuo. Si bien el matrimonio era imprescindible, no ponía un punto final a las frustraciones de la mujer. Y si la mayoría de las novelas femeninas de la época, escritas en gran parte por mujeres y pululando en forma de folletín en las revistas de señoras, tienen su eclosión en ese momento, es tal vez porque ahí comienza a evidenciarse una serie de discordancias en la correspondencia efectiva, cuyo análisis ofendería a la moral puritana. No podría ser de otro modo, cuando los tabúes rigurosos relacionados con las cuestiones sociales entregaban a las mujeres, sin ninguna preparación, a la experiencia del matrimonio; sin tomar en cuenta que la realidad de los hijos, multiplicándose cada año con el peligro siempre creciente de los partos, era muy diferente a la atmósfera de fantasía 
que poblaba de héroes el devaneo de la jovencita. Y si todavía hoy, después de más de un siglo de conquistas femeninas, la mujer se sigue moviendo como extraña en un mundo hecho por los hombres y en contradicción con su índole, en aquella época era, en verdad, la prisionera sumisa de un universo que, incomunicable, no sospechaba el fluir de su alma subterránea ${ }^{12}$.

El bloqueo de los seres, sin embargo, rara vez es absoluto y la sociedad siempre deja ciertas brechas por las cuales, entre un poco de luz, los impulsos se comunican con el mundo. Abandonada a sí misma, la mujer aplicó aquella curiosidad incansable de encontrarse, acentuada ciertamente por el ocio, en el interés por la moda. Mientras la sociedad le permitía al compañero el desarrollo integral de su individualidad en la profesión, la ciencia o las artes, a ella le negaba inquietudes de otro tipo que no estuvieran ligadas a la casa, a los hijos y a su persona. Era como si no tuviese cerebro, como si el ejercicio de la inteligencia tornase duros sus rasgos y empañase el brillo de la virtud ${ }^{13}$. Las preocupaciones del espíritu eran exclusivas del hombre, dueño de las artes, de la literatura y del destino de sus semejantes. Hecha de otra substancia, el terreno de ella era el salón mundano, donde asumía una nueva identidad a la que todos se rendían extasiados. En este sentido, vale la pena transcribir parte de la crónica social del 26 de julio de 1860 de la Revista Popular donde, refiriéndose a uno de los últimos bailes de la corte, se dan noticias detalladas de los vestidos y de sus dueñas:

El primero (vestido), el que causó mayor sensación, estaba hecho de moiré antigue color flor de romero, cubierto por un largo pliegue y una túnica de encaje de Bruselas; tanto aquel como este formaban un enfaldo sujetado por un delicado lazo de punto orlado del mismo encaje. La guarnición del corpiño, donde solo entraba el hilo de seda comprimido por estrechos dobleces, era

12 "Establezcamos antes que nada, que la cultura humana, incluso en sus contenidos más depurados, no es asexuada [...]. Nuestra cultura, en realidad, es enteramente masculina; a excepción de pequeñas esferas. Fueron los hombres quienes crearon el arte, la industria, la ciencia, el Estado y la religión" (Simmel 111). Véase también Simone de Beauvoir $(432,435)$.

13 La mujer intelectual, en el siglo XIX, es considerada repulsiva. He aquí como aparece descrita en una larga serie de artículos del Saturday Review, en 1867 y 1868: "Ella se esconde en organizaciones; adora a Kingsley, porque él es serio: difunde los sufrimientos de su sexo: considera a los viejos estúpidos y a los jóvenes insoportables. Su temperamento, como su rostro, es rígido y huesudo; interviene en la ciencia y se corta los cabellos, tratando de entrar en las conferencias del Prof. Huxley" (cit. en Cunnington, Feminine Attitudes 176-177). O, en otra serie de artículos, "The Grievances of Women”, aparecidos entre 1840 y 1850: “IImagínense a una mujer, linda, elegante, tomando parte en las riñas de una sacristía o entrando en el tumultuoso terreno de la política! ¡Dónde estarían entonces las pequeñas alegrías del hogar! [...] El sexo opuesto las ama, respeta, adora y así continuará siendo, mientras conserven esa inestimable joya: la "Virtud"' (cit. en Cunnington, Feminine Attitudes 118). 
rica y al mismo tiempo simple; pero, hay que confesarlo, la elegancia del traje era realzada por el porte majestuoso de la persona que con él se adornaba. La Sra. G. P., cuyos ojos lindos y expresivos no se dejaban vencer por los mil focos de luz desprendidos de los brillantes, que le adornaban el cuello, el pulso y el pecho, subyugaba con sus dotes naturales la belleza de los accesorios, que en parte los ocultaban.

Acompañaba a esta dama su hermana D. B., flor mimosa todavía en botón, que promete un deslumbrante florecer Alba, en medio de los blancos pliegues de su vestido de gasa repujado por un adorno, mal distinguiréis el suave respirar de su pecho puro y virginal. La túnica lisa, que servía de segunda enagua al vestido simple y modesto, estaba drapeada con una guarnición de hojas verdes; el adorno del corpiño se limitaba, igualmente, a un ramo de hojas y el prendedor del tocado se componía de una guirnalda verde y dorada [...] Los otros trajes que más me agradaron fueron los de las Sras. N. de la G. y C. M.; el primero sobresalía por el lujo, la riqueza y la perfección; la seda y la gasa se encontraban entrelazadas con arte y magnificencia, las perlas y los brillantes ligados con la juventud y la hermosura. El segundo se distinguía por la sencillez que presidiera su confección; la finura de la muselina sustituía las ondulaciones del muaré, los trazos verde-claro que cubrían el fino tejido abolían la idea de añadirle una cinta, un encaje, cualquier cosa que fuese para adornarlo: es así como se viste la candidez.

Pero al tener en la moda el único medio lícito de expresión, la mujer se abalanzó hacia el descubrimiento de su individualidad, inquieta y siempre insatisfecha, reconstruyendo por sí misma su propio cuerpo, aumentando exageradamente las caderas, comprimiendo la cintura, violentando el movimiento natural de los cabellos. Procuró en su ser - ya que no le quedaba otro remedio - la búsqueda de su mismidad, la pesquisa atenta de su alma. Y poco a poco, como el artista que no se somete a la naturaleza, impuso a la figura real una forma ficticia, reuniendo los pedazos dispersos en una concordancia necesaria: "llegada a la mitad de la vida Odette había finalmente descubierto o inventado una fisonomía personal, un 'carácter' inmutable, un 'género de belleza', y sobre sus rasgos fragmentados... había aplicado ese tipo fijo, como una juventud inmortal" (Proust, A l'ombre 26).

De esta manera, creaba una obra de arte con su propio cuerpo, sustituyendo la belleza natural por la belleza artística, producto de una disciplina del espíritu ${ }^{14}$.

14 "Pero podemos afirmar, contra esa opinión, que la belleza creada por el arte es inferior a la belleza natural, que la belleza artística es superior a la natural; porque es un producto del 
"El retrato era anterior a la época en que Odette, disciplinando sus rasgos, hiciera del rostro y del talle esa creación que, a través de los años, sus peinados, sus costureros, ella misma - en la manera de ser, de hablar, de sonreír, de pensar, de descansar las manos y los ojos- debía respetar a grandes líneas" (Proust, Le côté 133). En esa "alienación para el exterior", de la cual hablaba Hegel, creaba otro "sí-mismo", materializando los estados de su alma a través del espíritu del color y del tejido, sustituyendo a cada momento la atmósfera que la envolvía, así como el pintor varía el paisaje de fondo de su cuadro para impregnarnos del espíritu que lo posee (Hegel 1: 23) ${ }^{15}$.

Cada uno de sus vestidos me parecía un ambiente natural, necesario como la proyección de un aspecto particular de su alma. Una de esas mañanas de cuaresma en que iba a almorzar a la ciudad, la encontré con un vestido de terciopelo rojo claro ligeramente drapeado en el cuello. El rostro de Mme. de Guermantes parecía soñador bajo los cabellos rubios. Yo estaba menos triste que habitualmente porque la melancolía de su expresión, la especie de clausura que la violencia del color ponía entre ella y el resto del mundo, le daba algo de infeliz y solitaria que me calmaba. Ese vestido me parecía la materialización a su alrededor de los rayos escarlatas de un corazón que no conocía y que quizá pudiese consolar; refugiado en la mística luz del tejido de contornos suaves, ella me hacía pensar en alguna santa de las primeras eras cristianas. (Proust, Le coté 129)

Y añadiendo el gesto a la composición de líneas y colores, la mujer se transforma en una escultura fantasmal que no contiene en sí solo el "esbozo del movimiento", el "comienzo de la acción" de las esculturas reales; vive en la plenitud de la conquista del espacio, comunicándose con el ambiente en una conexión necesaria (Hegel 3: 106).

De pronto, sobre la arena de la alameda, lenta y lujuriosa, como la flor más bella que apenas se entreabre a la luz plena del sol, Mme. Swann aparecía, derramando a su paso un traje siempre diverso pero que, recuerdo, era sobre

espíritu. El espíritu, siendo superior a la naturaleza, comunica también su superioridad a sus productos y, por consiguiente, al arte. Es por esto que la belleza artística es superior a la belleza natural" (Hegel 1: 8).

15 "Mientras una obra de arte, en vez de expresar pensamientos y conceptos, representa el desarrollo del concepto a partir de él mismo, una alienación hacia afuera, el espíritu posee el poder de aprehenderse a sí mismo bajo la forma que le es propia y que es la del pensamiento, pero también de reconocerse como tal en su alienación bajo la forma del sentimiento y la sensibilidad; en resumen, de aprehenderse en ese otro sí mismo" (Hegel 1: 23). 
todo malva; entonces, al punto de su irradiación más completa, izaba y desdoblaba sobre un largo pedúnculo el toldo de sea de una gran sombrilla, del mismo tono que el deshojar en pétalos de su vestido. (Proust, $A$ l'ombre 52)

Es a través de esta caligrafía de los gestos como la mujer revela su alma contenida, reclusa, ligada a los objetos de los cuales se apodera armoniosamente, absorbiéndolos en su ritmo total. Encerrada en sí misma más por imposición de la sociedad que por una necesidad de su naturaleza ${ }^{16}$, reabsorbe el impulso artístico, sumergiendo toda su personalidad en la obra de arte que inscribe en lo cotidiano:

[...] de lejos vi, caminando en nuestra dirección, a la princesa de Luxemburgo, ligeramente apoyada en una sombrilla, como para imprimir a su gran y deslumbrante cuerpo una suave inclinación, haciéndole diseñar aquel arabesco tan preciado en las mujeres que eran bellas durante el Imperio y que a pesar de los hombros caídos, el dorso curveado, el costado retraído, la pierna rígida, sabían hacer que el cuerpo fluctuara como un pañuelo alrededor del armazón invisible de un asta inflexible. (Proust, Le côté 136)

Esa creación artística, poderoso elemento en la lucha entre los sexos, con la cual la mujer realiza la búsqueda de su ser, es todavía el elemento de diferenciación personal dentro del grupo. Pues, no es tanto el vestido - la opulencia de los tejidos y la exuberancia de los volantes-, sino la manera de utilizarlo, de hacerlo concordar con su cuerpo y con su alma, de imprimir el movimiento a la estructura total, lo que distingue a las mujeres entre sí. No es el cuadro estático, sino toda esa orquestación de gestos que se revela en el recogimiento de las faldas, en el esconderse detrás del abanico, en el aproximar la mantilla o el chal al cuerpo, en el levantar lánguidamente la sombrilla sobre el hombro ${ }^{17}$. Pues así como aceptó

16 En su ensayo "Cultura femenina" (en Cultura femenina y otros ensayos), Simmel defiende el punto de vista según el cual la mujer es un ser unitario por excelencia, pues le falta a ella "esa cualidad tan masculina de mantener intacta la esencia personal incluso cuando se dedica a una producción especializada, que no implica la unidad del espíritu". Cada una de las actuaciones de la mujer, por el contrario, "pone en juego la personalidad total y no separa el yo de sus centros sentimentales". De allí que se realice plenamente solo en las artes del espacio (16-17), como en el arte teatral, donde efectúa la inmersión integral de la personalidad en la obra o fenómeno artístico (34 ss.). Sin embargo, ¿hasta dónde ese temperamento unitario no será fruto de factores sociales? "La convicción creciente, basada en la evidencia psicológica, es que los rasgos de la personalidad son 'productos derivados de intereses inmediatos e incentivos' y se desenvuelven de acuerdo al papel social del individuo en una cultura determinada. Entre las circunstancias que determinan ese papel, el sexo es apenas uno de los elementos" (Klein 170). "Pues había una sutil distinción de clase en la manera adecuada de levantar la larga falda. Mientras la mujer francesa empleaba las dos manos para erguir ambos lados, la 'lady' inglesa 
la moral relacionada con los hábitos del cuerpo, la mujer desarrolló infinitamente las artes relacionadas con su persona creando un estilo de existencia; quizá su única contribución original a la cultura masculina.

Por esta razón, cuando desde la segunda mitad del siglo XIX en adelante ella comenzó a interesarse por las profesiones, se encontró frente a una encrucijada. La carrera exclusiva del hombre entendida, como vimos, en términos de austeridad en el vestir la obligaba a desinteresarse del adorno y a renunciar al comportamiento narcisista, como ya las institutrices lo habían hecho o como lo harán también las "sufragistas". Pero no se desiste impunemente de bellos hábitos que años de vida encerrada desarrollaron como una segunda naturaleza. Y lanzándose en el áspero mundo de los hombres, la mujer se vio lacerada entre dos polos, viviendo simultáneamente en dos mundos, con dos tipos de valores distintos ${ }^{18}$. Para vivir dentro de la profesión se adaptó a la mentalidad masculina de la eficiencia y el despojamiento, copiando los hábitos del grupo dominante, en su manera de vestir, desligándose de todo aquello que, por ser característico de su sexo, surgía como símbolo de inferioridad: el brillo de los vestidos, la gracia de los movimientos, la ondulación del cuerpo ${ }^{19}$. Y si en la profesión era siempre vista un poco como un diletante, dentro de su grupo, donde los valores aún se relacionaban con el arte de seducir, representaba un verdadero fracaso. No es de

recogía los bordes de la tela con la punta de los dedos, suspendiendo la falda hasta las caderas para finalmente descansar la mano en la cintura, sin girar el codo. Se distinguía así también del vulgar populacho, cuyos codos se proyectaban hacia afuera, comprometiendo las curvas rítmicas" (Cunnington, The Perfect 66). "El arte del chal es estudiado; produce bellas actitudes y su arreglo denota el nivel social" (Cunnington, Feminine Attitudes 96).

18 Viola Klein observa que sería interesante adoptar en el estudio del grupo femenino el punto de vista de Stonequist en The Marginal Man, es decir, estudiarlo como una minoría oprimida: "Otro punto de vista interesante y fructífero sería la comparación entre los rasgos de personalidad de la mujer y de los otros grupos sociales en situación análoga; a saber: los inmigrantes, judíos, conversos, pueblos conquistados, negros americanos, nativos occidentalizados, intelectuales, que rompieran con los grupos sociales y las clases en que se originaron pero que aún no se hubieran liberado completamente de los lazos que los unen a ellos".

19 Se sabe que las reivindicaciones femeninas han sido acompañadas por modas masculinas, fenómeno bastante nítido en la postguerra del 1914-1918. El decenio de los años 20, por ejemplo, estipuló para la mujer una forma asexuada, los chalecos, y transformó el cuerpo en un cilindro. Una curiosa manifestación de ese sentimiento de inseguridad e inferioridad de las mujeres en relación con el grupo masculino han sido los "robos" de piezas de la indumentaria de los hombres, realizados a medida que el movimiento de emancipación femenina fue progresando. Reivindicando para las mujeres los mismos derechos de los hombres, la primera cosa que hicieron las "sufragistas" fue inventar los bloomers. Pero veamos algunos de esos hurtos: a principios de siglo, los pantalones (lingerie); en 1850, el chaleco; en 1860, la camisa, el collarín y la corbata; en 1870, la ropa tailor-made. Bajo el liderazgo de la joven princesa Alexandra, los sastres de señoras hacen vestidos de falda y chaqueta (Davenport 797). 
sorprender que ese desgarramiento haya llevado a la mujer al estado de inseguridad y duda que perdura hasta hoy. Puesto que perdió su elemento más poderoso de afirmación y todavía no adquirió aquella confianza en sí misma que siglos de trabajo implantaran en el hombre.

Sin embargo, es posible que aún encuentre un denominador común entre los valores de su grupo y los del grupo masculino, aprendiendo a inscribir en el nuevo curso de su vida aquellos elementos que se grabaron en su individualidad y forman parte de su ser. Así, combinando la gracia con la eficiencia, encontrará un nuevo equilibrio, tan armonioso como el estilo de vida de la mujer del siglo XIX.

\section{Obras citadas}

Alencar, Jose de. Senhora. Perfil de mulher. Río de Janeiro: B. L. Garnier, 1875.

Beauvoir, Simone de. El segundo sexo. 1942. Madrid: Cátedra, 1998.

Benedict, Ruth. "Dress". Encyclopedia of the Social Sciences 5: 235-237.

Brontë, Charlotte. Fane Eyre. 1847. Edimburgo; Glasgow;

Londres: H. Milford; Oxford University Press, 1920.

Cunnington, Willett C. English Women's Clothing in the Nineteenth

Century. Nueva York: Faber and Faber, 1948.

-. Feminine Attitudes in the Nineteenth Century. Londres: Heinemann, 1935.

-. Feminine Fig-Leaves. Londres: Faber and Faber, 1938.

-. The Perfect Lady. Londres: Max Parrish, 1948.

Davenport, Millia. The Book of Costume. Nueva York: Crown Publishers, 1948.

Flügel,J. C. "Compte-rendu". Revue Française de Psychanalyse 4.4 (1930-1931).

—. "De la valeur affective du vêtement". Revue Française de Psychanalyse 3.3 (1929).

-. The Psychology of Clothes. Madison: International Psychanalyse Library, 1930.

Hegel, Friedrich. Esthétique. Tomos 1 y 3. París: Aubier, 1944.

Klein, Viola. The Feminine Character: History of an Ideology.

Nueva York: International Universities Press, 1948.

Macedo, Manuel de. A moreninha. 1844. São Paulo: Abril Educação, 1981.

-. Rosa. 1849. Río de Janeiro: Livraria Granier, 1910.

Laver, James. Letter to a Girl on the Future of Clothes. Londres: Home \& Van Thal, 1946.

-. Taste and Fashion. From the French Revolution until Today.

Bombay; Londres: George G. Harrap, 1937.

Machado de Assis, Joaquim Maria. Dom Casmurro. París:

Inst. International de Coop. Intellectuelle, 1936.

-. Helena. 1876. Río de Janeiro: Nova Aguilar, 1994.

Marañon, Gregorio. Gordos y flacos. Madrid: La Lectura, 1926.

Percival, Alicia. The English Miss To-Day and Yesterday. Londres: Harrap, 1939. 
Proust, Marcel. A l'ombre des jeunes filles en fleurs. Tomo 2. París: Gallimard, 1919.

—. Le côté de Guermantes. Tomo 1. París: Gallimard, 1922.

Schlesinger, Arthur M. Learning How to Behave. A Historical Study of American Eriquette Books. Nueva York: Macmillam, 1946.

Simmel, George. Cultura femenina y otros ensayos. Buenos Aires: Espasa, 1944.

Stonequist, Everett V. The Marginal Man: A Study in Personality and Culture Conflict. Nueva York: Russell \& Russell, 1961.

Thackeray, William Makepeace. Vanity Fair. 1847. Londres: Heron Books, 1969. 